\title{
Understanding online business simulation games: the role of flow experience, perceived enjoyment and personal innovativeness
}

\author{
Jorge Matute-Vallejo \\ Universitat Ramon Llull, Barcelona, Spain \\ Iguácel Melero-Polo \\ Universidad de Zaragoza, Huesca, Spain
}

\begin{abstract}
This study aimed to empirically predict the degree of acceptance of an online business simulation game in an educational context. To do so, this study proposed an extended technology acceptance model that includes variables such as perceived enjoyment and flow. In addition, the moderating role of students' personal innovativeness in the technology field was analysed. The framework was empirically tested applying partial least squares to a sample of 266 students. Results reveal that perceived enjoyment is a key variable in explaining students' perceived ease of use, usefulness and attitudes towards the simulation. Perceived ease of use is not significantly related to flow experience. However, this relationship is moderated by personal innovativeness. Indeed, results indicate that the higher the students' personal innovativeness, the more attenuated the effect of perceived ease of use on the attitude towards the game and on flow experience. The study offers relevant insights for the pedagogical use of competitive digital technologies in university contexts.
\end{abstract}

\section{Introduction}

During the last two decades, society has been focused on revolutionary technological advancements that have enabled individuals to interact and look for information more easily, quickly, flexibly and efficiently (Roca, Chiu, \& Martínez, 2006; Lauricella, Blackwell, \& Wartella, 2017). Education has also adapted to the new technological scenario by taking advantage of the benefits that new information technologies (ITs) provide. Within this context, innovative educational techniques have recently emerged to improve learning experience. One of these pedagogical tools is the use of business simulation games. Games are defined as "goal-directed, a competitive activity (against the computer, another player or oneself), and conducted within a framework of agreed rules" and a simulation is understood as "a simplified model of reality structured as a system which includes specified variables and dynamic relationships between them” (Ranchhod, Gurău, Loukis, \& Trivedi, 2014, p. 76). Recent research reveals that the use of simulation games in education has numerous positive learning outcomes (e.g., All, Nuñez Castellar, \& Van Looy, 2016; Boyle et al., 2016; Buil, Catalán, \& Martínez, 2018; Pando-García, Periañez-Cañadillas, \& Charterina, 2016; Wellington, Hutchinson, \& Faria, 2017).

Research acknowledges that in the context of digital game-based learning, both usefulness and ease of use are important predictors of students' acceptance (Pando-García et al., 2016). However, recent research also suggests that the influence of these variables is still unclear and that other variables should complement the technology acceptance model (TAM) (Davis, 1989), especially when different motivations to use the technology emerge (All, Nuñez Castellar, \& Van Looy, 2015; Bourgonjon, Valcke, Soetaert, \& Schellens, 2010). First, for example, studies point out that the effectiveness of digital game-based learning should be evaluated by assessing the degree to which students have an enjoyable experience (Boyle et al., 2016; CelaRanilla, Esteve-Mon, Esteve-González, \& Gisbert-Cervera, 2014; Filippou, Cheong, and Cheong, 2018). This is especially significant in the context of simulation games, where students may perceive the activity as enjoyable in its own right, apart from the implicit learning purpose inherent in educational games. Second, according to the study of All et al. (2015), an additional element of simulation games effectiveness is tied to time management. Educational games design must focus on providing experiences that enable students to achieve specific learning goals in reduced time frames (Hamari et al., 2016). Flow theory suggests that flow makes the activity intrinsically rewarding (Smets, Abbing, Neerincx, Lindenberg, \& van Oostendorp, 2010) and that higher levels of immersion with the game are associated with increased learning performance (Hamari 
et al., 2016). And third, studies have demonstrated individual differences in how the benefits of game-based technologies are perceived (Koivisto \& Hamari, 2014). However, little is known about the role that personality may play in explaining students' acceptance of these educational games (Hamari et al., 2016). It is critical to recognise how students' willingness to try new technologies affect their evaluation of the learning experience. In these learning environments, more innovative individuals will be more likely to be influenced by intrinsic motivation (Herrington, Oliver, \& Reeves, 2003). However, the attitudes and feelings of less innovative students may be strongly affected by the fact that the technology is perceived as friendly to use.

To fill theses gaps in the literature the general purpose of this study was to analyse how students' perceptions, personality traits and experiences with an online business simulation game (OBSG) explain their attitudes towards it. To do this, an extended TAM was proposed and tested in order to better understand the acceptance of college students of the OBSG. Thus, this study aimed to explore the following research questions:

- What is the role of perceived enjoyment in explaining the success of the OBSG? How does enjoyment determine students' perceptions of the game's ease of use and usefulness, flow experience and attitudes related to the game?

- How the flow experimented during the game can explain the students' evaluations of the learning experience in the context of the OBSG? Does flow experience depend on students' intrinsic motivations and perceptions on the game such as perceived ease of use and usefulness?

- Is the influence of perceived ease of use and enjoyment on attitudes and flow moderated by the students' degree of personal innovativeness? Does this personality trait explain heterogeneous reactions to the use of the OBSG in learning environments?

The study was organised as follows. In the next section, the authors describe the theoretical framework and present the research hypotheses. Subsequently, the research methodology and the data used to empirically test and validate our conceptual framework are described. Then, the manuscript presents the empirical results and concludes with a discussion of the main findings and contributions of the article. Finally, the study's limitations and a set of directions for future research are highlighted.

\section{Conceptual framework and hypotheses development}

The TAM is widely employed to explain how users may accept and use a specific innovative technology (Pando-García et al., 2016). The TAM establishes that perceived ease of use and perceived usefulness are the two primary predictors of individuals' attitudes towards the technology (Davis, 1989). Perceived ease of use makes reference to "the degree to which a person believes that using a particular system would be free of effort" (Davis, 1989, p. 320). Perceived usefulness is defined as the degree to which a person believes that using a particular system would enhance his/her job performance (Davis, 1989, p. 320). Furthermore, perceived ease of use has a positive influence on perceived usefulness (Bourgonjon et al., 2010). Finally, perceived ease of use and perceived usefulness predict an individual's attitude towards the technology (Pando-García et al., 2016). This attitude towards using a technology is defined as an individual's positive or negative feelings about performing a specific behaviour (e.g., using technology) (Teo \& Noyes, 2011).

According to the high degree of consensus that exists in the literature regarding the TAM, the present research revalidates this model's relationships in the context of an OBSG. This study also developed an extended TAM in order to better explain the technological acceptance of an OBSG in an educational context. To do this, the model includes the role of perceived enjoyment and flow experience within the TAM and proposes personal innovativeness as a moderator of some of the proposed relationships. Figure 1 summarises the conceptual model. 


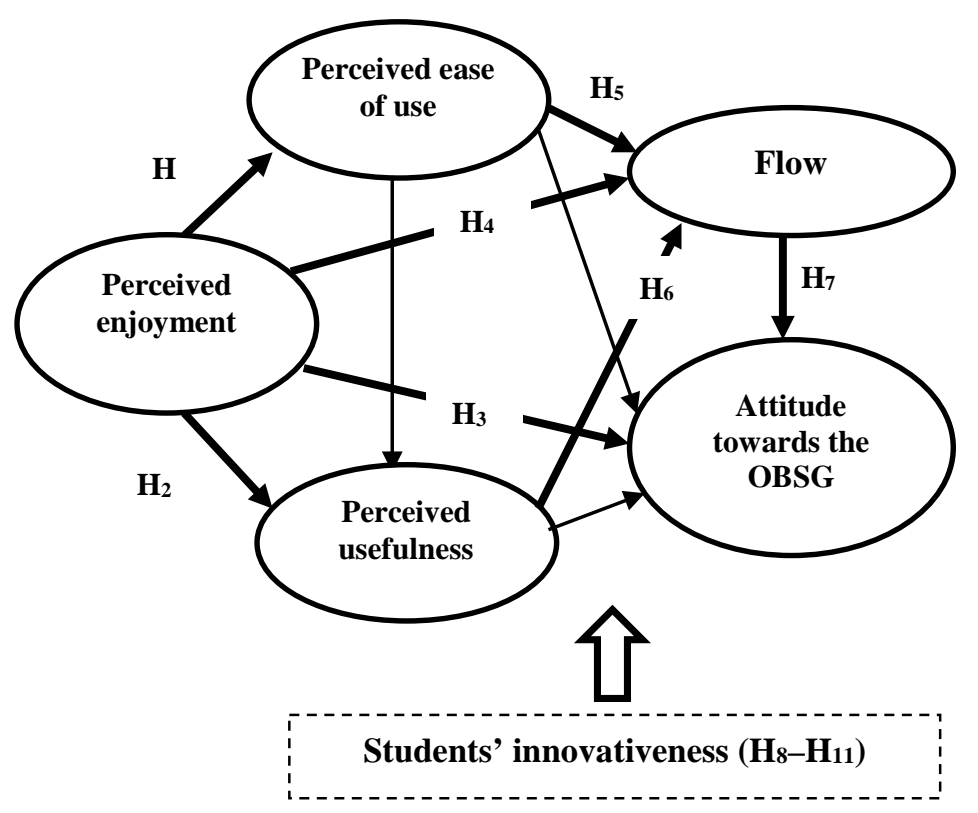

Figure 1. Theoretical model

\section{Perceived enjoyment}

Perceived enjoyment is defined as the "degree to which the activity of using technology is perceived to be enjoyable in its own right apart from any performance consequences that may be anticipated" (Davis, Bagozzi, \& Warshaw, 1992, p. 1113). Enjoyment is conceived as the pleasure that students feel while they are interacting with the OBSG (All et al., 2015). In spite of the fact that simulation games must provide students with enjoyment (All et al., 2015; Ha, Yoon, \& Choi, 2007), this variable has been rarely included in studies of technology acceptance in educational contexts (Teo \& Noyes, 2011)

Research has proposed that perceived enjoyment is a key determinant of perceived ease of use (Venkatesh, 2000; Venkatesh, Speier, \& Morris, 2002). The reason for this causal direction is that perceived enjoyment may make individuals underestimate the difficulties related to use of the technology (Sun \& Zhang, 2006). As students are entertained using the OBSG and enjoy the process of interacting with it, any difficulties that appear will be perceived as less complicated so their fears and reluctance regarding the use of a new technology may be mitigated. Consequently, the OBSG will be perceived as easier to use, making it more intuitive and less challenging to handle; thus, it is proposed that:

$\mathrm{H}_{1}$ : Students' perceived enjoyment of the OBSG has a positive effect on perceived ease of use of the OBSG.

Perceived enjoyment of a technology may also determine its perceived usefulness. Although some games are designed only to provide pleasure and enjoyment, others have a utilitarian component such as an educational purpose (Ha et al., 2007). Agarwal and Karahanna (2000) suggested that enjoyable technologies will be perceived as more useful because while individuals are enjoying interacting with the technology, they are not aware that they are also being more productive and effective. In this educational context, students may not be aware that they are learning at the same time that they are having fun playing the OBSG. Despite its potential importance, this relationship has been rarely studied in the literature. Thus, it is hypothesised that:

$\mathrm{H}_{2}$ : Students' perceived enjoyment of the OBSG has a positive effect on the perceived usefulness of the OBSG. 
Enjoyment can also influence users' attitudes towards the technology (Ahn, Ryu, \& Han, 2007; Wu \& Liu, 2007). During the learning process, users who enjoy using the technology are more likely to have a positive attitude towards it (Lee, Cheung, \& Chen, 2005). In the context of online gaming, players who perceive games as enjoyable are more prone to express enhanced satisfaction levels (Wu \& Liu, 2007). This satisfaction will drive improved evaluations of the technology, which means that these individuals will have a better attitude towards using it. Following these arguments, it is proposed that:

$\mathrm{H}_{3}$ : Students' perceived enjoyment of the OBSG has a positive effect on their attitude towards the OBSG.

\section{Flow experience}

Flow is understood as the holistic experience that people feel when they act with total involvement (Csikszentmihalyi, 1990). People in a flow state become completely absorbed in their activity and, as they lose self-consciousness, perceive hardly any external stimulus because nothing else seems to matter (Gao et al., 2016; Hsu \& Lu, 2004). Literature has shown that flow has a positive effect on learning results and must be considered when digital learning materials are designed (Buil, Catalán, \& Martínez, 2017; Lai, Lim, \& Wang, 2016).

Studies have suggested that perceived enjoyment leads to a flow state (Hamari et al., 2016). Individuals who are enjoying the experience of interacting with the technology and perceive that time flies while they are focused on its performance, will be more prone to achieve a flow state (Ha et al., 2007). Indeed, such a feeling of time distortion is especially frequent when people are having fun (Agarwal \& Karahanna, 2000). Therefore, it is suggested:

$\mathrm{H}_{4}$ : Students' perceived enjoyment of the OBSG has a positive effect on the flow experience.

In addition, when a technology is easy to use, the individual will be more likely to fall into a flow state (Kiili, 2005). This happens because the individual does not have to be focused on learning how to use the technology first, as it is easy from the beginning. Thus, the user can invest all their efforts into interacting with the technology. On the contrary, when there is no perception of ease of use, the individual sacrifices attention and cognitive resources to understand the technology, which decreases their possibility of experiencing flow (Kiili, 2005; Zhou, 2013). In these situations, the student will be more likely to fall into states of anxiety. On the contrary, if the game is perceived as easy to handle, students will more easily fall into states of higher immersion and concentration, which are both characteristics of flow. Hence:

$\mathrm{H}_{5}$ : Students' perceived ease of use of the OBSG has a positive effect on the flow experience.

Perceived usefulness can also lead to an increased level of flow. When the technology is useful for individuals and provides challenging tasks, the possibility that they experience flow, increases (Finneran \& Zhang, 2003). In contrast, if there are no challenging tasks (i.e., the individual does not perceive usefulness), they will not experience a flow state (Kiili, 2005). Consequently, it is expected that in the OBSG context, if students perceive that the game allows them to more efficiently learn or achieve the specific learning competences, they will be more likely to experience states of flow. However, if students consider that the OBSG does not allow them to be more productive, they will be more likely to disconnect from the game experience, which will prevent them from falling into a flow state. Hence:

$\mathrm{H}_{6}$ : Students' perceived usefulness of the OBSG has a positive effect on the flow experience.

Flow can also improve the individuals' attitudes towards using the technology (Novak, Hoffman, \& Yung, 2000). Research has indicated that if the utilisation of a technology enables individuals to enter into a state of flow, those individuals should ultimately be able to improve their well-being through accumulated ephemeral moments (Hsu \& Lu, 2004). Thus, as individuals become so involved in the task they are performing that they have no notion of time (Hamari et al., 2016), their attitudes towards the technology will improve. Consistent 
with these arguments, if the OBSG is able to absorb the students, this is because it has been effective in catching individuals' attention and in generating positive attitudes. In this sense, it is proposed that:

$\mathrm{H}_{7}$ : The flow experienced by students during the OBSG has a positive effect on their attitude towards the OBSG.

\section{The moderating role of individuals' innovativeness}

This study focuses on one key personality variable that may help to better explain students' individual personalities: their individual level of innovativeness in the field of ITs. Broadly understood, innovativeness refers to "whether individuals are willing to adopt products or ideas that are new in the context of their individual experience” (Aldás-Manzano, Ruiz-Mafé, \& Sanz-Blas, 2009, p. 740) or in the specific context of technologies, to "the degree to which an individual is willing to try out any new information technology" (Lee, Ahn, \& Han, 2007, p. 1097). Adapting this definition to our educational and technological context, innovativeness is understood as the students' willingness to adopt innovative technologies that are new to them.

Research suggests that some aspects of innovativeness influence attitudes towards technological products (Dabholkar \& Bagozzi, 2002). Innovative consumers in the field of ITs tend to favour the use of technologybased products, have stronger intrinsic motivations to experiment with them and enjoy trying new ways to solve problems by interacting with new technologies (Dabholkar \& Bagozzi, 2002). Highly innovative individuals will not be concerned about the technologies' ease of use and will be willing to try them out no matter how complex and unreliable the technologies seem. Thus, the influence of perceived ease of use in the formation of the individuals' attitudes towards and evaluation of the technology will not be as relevant in innovative people. Hence:

$\mathrm{H}_{8}$ : Students' personal innovativeness negatively influences the positive relationship between perceived ease of use of the OBSG and attitude towards the OBSG.

Following Dabholkar and Bagozzi (2002), individuals who are more prone to seek out novelties and are open to new experiences will also see innovative technologies as more stimulating. Thus, if the individual is highly innovative, the influence of the perceived enjoyment on the formation of the individual's attitude will be stronger. Therefore, it is formulated:

$\mathrm{H}_{9}$ : Students' personal innovativeness positively influences the positive relationship between perceived enjoyment of the OBSG and attitude towards the OBSG.

Research has also indicated that individual traits are likely to have an effect on experiential states (Wild, Kuiken, \& Schopflocher, 1995). Agarwal and Karahanna (2000) suggested that individuals who have an innate propensity to be more innovative with technologies are more likely to be predisposed to experience episodes of cognitive absorption. Since more innovative individuals will not need to invest efforts in learning how the technology works, and will be more immersed in interactions with technology, the effect of perceived ease of use on flow will be attenuated by personal innovativeness. Hence:

$\mathrm{H}_{10}$ : Students' personal innovativeness negatively influences the positive relationship between perceived ease of use of the OBSG and flow experience.

On the contrary, innovative individuals will be more prone to experience states of flow as a consequence of enjoying their interactions with the technology. For these innovative individuals, intrinsic motivations will be more relevant in explaining states of time distortion than for those individuals that do not enjoy the stimulation of trying new technology-based products. Consequently, it is proposed:

$\mathrm{H}_{11}$ : Students' personal innovativeness negatively influences the positive relationship between perceived enjoyment of the OBSG and flow experience. 


\section{Methodology}

\section{Sample and context}

This study uses data gathered from undergraduate students that participated in an OBSG. These students were enrolled in an elective marketing course in their fourth year of a degree in business management at the Faculty of Economics and Business Management of the University of Zaragoza in Spain. The University of Zaragoza is one of the 15 largest public universities in Spain with more than 30,000 students. During one semester, teams of students managed different companies in an online competitive scenario. Four or five students composed the teams and there were, on average, 25 students in every class. The OBSG was an integral component of the marketing course entitled "Marketing Decision Making”.

\section{The OBSG}

The simulation required students to manage a business operating in the climate control products industry in a global scenario. The game was a competitive web-based simulation where teams in each class were competing against other teams of students within the same class. Every team of students was provided with a username and a password, but access to the game was available only during class time. Every team had to manage a company producing and distributing three different products in three different geographical markets. The game was designed in such a way that students had to make strategic and operational decisions in different periods of the virtual trimesters. At the end of each trimester, students obtained a score report containing information about their company's and the competitors' performance. The total number of terms played was 12, which corresponds with three virtual years in the game. The course schedule was designed as follows:

- The two first weeks of the semester instructors explained the game's methodology and the software, introducing students to the game's contents, scenarios, decisions and procedures.

- Two non-assessed trial terms were played in order to enable students to gain familiarity with the software.

- During the following eight weeks, students had to make operational and strategic decisions. Once all the teams within the same scenario had completely undertaken their decisions, instructors processed the plays and students were able to access the scores and start the planning of the next virtual trimester.

- The last two weeks of the course were dedicated to oral presentations where students had to explain and defend the tactics and strategies followed by their companies during the game.

The game was designed according to the theoretical and practical marketing competences acquired by students in the previous years of the degree. The game technical development was carried out by an IT Spanish company expert in the design of gamification solutions for educational and managerial purposes. The game required students to be in charge of the marketing decisions of a company; assess the elements of the external environment that may influence their company's activities; analyse the competitive dynamics within the market; make strategic and operational decisions in the marketing area; and critically examine the consequences of their decisions for planning future actions. The structure of decisions in the game were divided in different areas:

- Finance: Students could obtain information about the company's accounting and financial matters.

- Production: Students had to calculate the production orders to meet market demand.

- Marketing: Students had to make decisions related to product, pricing, placement advertising and media planning.

- Human resources: Students had to make decisions related to salaries, as well as training, hiring and firing of their salespeople.

- Information: Students could access a description of their company's starting situation and other relevant competitive information. Additionally, they could buy different market research reports.

- Scoring: Students could access to their own and their competitors' scores. 


\section{Data collection procedure and measurement instruments}

Data was collected through a self-administered survey. This study gathered data across the academic years 2013-2014 and 2014-2015. The course design did not vary from one year to the other. The survey included randomly ordered questions. The course instructors explained to the students that the goal of the survey was to gather information in order to analyse their experience with the game. Participation in the survey was voluntary and students were advised that it would not affect their grades. Additionally, anonymity and data confidentiality were also guaranteed. The survey was administered in five classes in the first year and in seven classes in the second year. Almost $100 \%$ of the students agreed to participate in the study. Thus, the sample was representative of the total population composed of all the students who participated in the course. A total of 266 questionnaires were considered valid. Of the sample, $53.4 \%$ was male, while $46.6 \%$ was female. $t$-tests to explore mean differences between the two years and between the different groups were performed; no significant differences were found.

The variables included in the study were measured with 7-point Likert scales ( 1 = strongly disagree; 7 = strongly agree). Table 1 presents the measurement instruments and their Cronbach's alpha values. To measure perceived usefulness, perceived ease of use and attitude towards the game, slightly modified versions of validated scales employed in the TAM literature were employed (Davis et al., 1992; Venkatesh, 2000). Similarly, perceived enjoyment was measured with Sun and Zhang's (2006) instrument. Flow was measured by adapting the validated instruments by Hsu and Wu (2004) and Ha et al. (2007). The flow scale was composed of four items that were originally in Novak et al.'s (2000) work. Finally, the scale on personal innovativeness was composed of three items from Agarwal and Prasad (1998) and Agarwal and Karahanna (2000).

Table 1

Measurement scales

\begin{tabular}{lc}
\hline Scale & $\alpha$ \\
\hline Perceived ease of use (PEU) & 0.860 \\
\hline PEU1. The OBSG is easy to use. & \\
\hline PEU2. Interacting with the OBSG is easy to understand. & 0.928 \\
\hline PEU3. Learning to operate the OBSG is easy for me.
\end{tabular}

PU1. Using the OBSG can increase my learning effectiveness.

PU2. Using the OBSG can improve my learning performance.

PU3. I find the OBSG useful for my education.

\begin{tabular}{lc}
\hline Attitude towards the OBSG (ATT) & 0.922 \\
\hline ATT1. I have a positive opinion about the OBSG. & \\
ATT2. I like using the OBSG. & \\
ATT3. I think that using the OBSG is a good idea. & 0.925 \\
\hline Perceived enjoyment (PE) & \\
\hline PE1. I have fun using the OBSG. & 0.871 \\
\hline PE2. I enjoy participating in the OBSG. & \\
PE3. Using this OBSG entertains me. & \\
\hline Flow experience (FLO) & \\
\hline FLO1. Time flies when I am using the OBSG. & \\
FLO2. I feel I am in flow while I am using the OBSG. & \\
FLO3. In general, how frequently would you say you experienced “flow” when you play & \\
the OBSG (1 = never; 7 = continuously). & \\
FLO4. Most of the time when I was using the OBSG I felt absorbed and focused on it. & \\
\hline Personal innovativeness with information technologies (INN) & \\
\hline INN1. If I hear about a new information technology, I look for ways to experiment with \\
it.
\end{tabular}




\section{Data analysis procedures}

The proposed model was tested with partial least squares (PLS) regressions with SmartPLS 3.0 software. PLS is a distribution-independent structural equation modelling method that has fewer constraints and statistical assumptions than traditional covariance-based estimations. PLS is primarily intended for causal-predictive analysis in research contexts of complexity (Roldán \& Sánchez-Franco, 2012). This methodology is appropriate when the interest of the study focuses on prediction, or theory building, rather than on theory confirmation. In addition, it is considered to be well suited when the research has an interactive character (Roldán \& SánchezFranco, 2012). This is the case of our study, which was initially based on a confirmed model, such as the TAM, but new variables and structural paths were introduced into it. In addition, the use of PLS is preferable when the model, as in this case, is complex or includes a large number of indicators, latent variables and relationships (Hair, Ringle, \& Sarstedt, 2011). Finally, according to research, PLS should be the method of choice for all situations in which the number of observations is lower than 250 or 400 in the case of less reliable measurement models (Reinartz, Haenlein, \& Henseler, 2009).

Common method bias was controlled using three methods. First, guaranteeing students that the information provided in the survey was confidential and anonymous reduces their tendency to respond artificially (Podsakoff, MacKenzie, \& Podsakoff, 2003). Second, the variables were randomly introduced in order that the students could not infer cause-effect relationships among constructs. Additionally, three different versions of the survey that presented different sequences of the questions were designed. Finally, exploratory factor analysis within SPSS confirmed that one single factor did not explain the highest proportion of the data variance (Table 2). Furthermore, items did not load on a large unique factor that accumulated the majority of this variance.

Table 2

Results of the exploratory factor analysis

\begin{tabular}{|c|c|c|c|c|c|c|}
\hline \multirow[t]{2}{*}{ Item } & \multicolumn{6}{|c|}{ Factor } \\
\hline & 1 & 2 & 3 & 4 & 5 & 6 \\
\hline FLO1 & .634 & .014 & .410 & .100 & .138 & .227 \\
\hline FLO2 & .844 & .150 & .171 & .119 & .093 & .131 \\
\hline FLO3 & .873 & .171 & .116 & .101 & .033 & .050 \\
\hline FLO4 & .782 & .109 & .222 & .143 & .088 & .085 \\
\hline PU1 & .142 & .875 & .127 & .032 & .151 & .240 \\
\hline PU2 & .181 & .867 & .236 & .065 & .124 & .201 \\
\hline PU3 & .128 & .814 & .147 & .085 & .156 & .322 \\
\hline PEU1 & .162 & .100 & .115 & .035 & .871 & .044 \\
\hline PEU2 & .070 & .179 & .028 & .076 & .836 & .163 \\
\hline PEU3 & .024 & .094 & .146 & .104 & .851 & .199 \\
\hline ATT1 & .163 & .327 & .193 & .122 & .253 & .799 \\
\hline ATT2 & .224 & .287 & .361 & .041 & .170 & .769 \\
\hline ATT3 & .110 & .420 & .226 & .066 & .168 & .762 \\
\hline PE1 & .321 & .222 & .804 & .104 & .111 & .187 \\
\hline PE2 & .311 & .207 & .802 & .175 & .110 & .282 \\
\hline PE3 & .206 & .169 & .826 & .180 & .129 & .189 \\
\hline INN1 & .097 & .031 & .190 & .839 & .090 & .108 \\
\hline INN2 & .096 & .035 & .049 & .913 & .063 & .044 \\
\hline INN3 & .177 & .089 & .108 & .901 & .055 & .014 \\
\hline
\end{tabular}

Note. See Table 1 for abbreviations.

Individual reliability was examined by analysing the factor loadings of every manifest variable in each respective latent variable. All the loadings were above the recommended level of 0.7 . Reliability of the survey instrument was also confirmed by calculating the scales' composite reliability to measure internal consistency. 
The composite reliability indexes of the latent variables were above the suggested benchmark of 0.7 (Roldán \& Sánchez-Franco, 2012). The constructs also met convergent validity criteria. The average variance extracted (AVE) values were above 0.5 (Fornell \& Larcker, 1981). Results of the measurement model are shown in Table 3.

Table 3

Measurement model: reliability and validity

\begin{tabular}{|c|c|c|c|c|}
\hline Construct & Indicators & $\begin{array}{c}\begin{array}{c}\text { Standardised } \\
\text { loading }\end{array} \\
\end{array}$ & $\begin{array}{c}\text { Composite } \\
\text { reliability index }\end{array}$ & AVE \\
\hline \multirow{3}{*}{ Perceived ease of use (PEU) } & PEU1 & 0.874 & \multirow{3}{*}{0.914} & \multirow{3}{*}{0.781} \\
\hline & PEU2 & 0.880 & & \\
\hline & PEU3 & 0.897 & & \\
\hline \multirow{3}{*}{ Perceived usefulness (PU) } & PU1 & 0.934 & \multirow{3}{*}{0.954} & \multirow{3}{*}{0.874} \\
\hline & PU2 & 0.947 & & \\
\hline & PU3 & 0.923 & & \\
\hline \multirow{3}{*}{ Attitude (ATT) } & ATT1 & 0.934 & \multirow{3}{*}{0.951} & \multirow{3}{*}{0.865} \\
\hline & ATT2 & 0.935 & & \\
\hline & ATT3 & 0.922 & & \\
\hline \multirow{3}{*}{ Perceived enjoyment (PE) } & PE1 & 0.958 & \multirow{3}{*}{0.952} & \multirow{3}{*}{0.870} \\
\hline & PE2 & 0.934 & & \\
\hline & PE3 & 0.905 & & \\
\hline \multirow{4}{*}{ Flow experience (FLO) } & FLO1 & 0.822 & \multirow{4}{*}{0.912} & \multirow{4}{*}{0.720} \\
\hline & FLO2 & 0.879 & & \\
\hline & FLO3 & 0.851 & & \\
\hline & FLO4 & 0.845 & & \\
\hline \multirow{3}{*}{ Personal innovativeness (INN) } & INN1 & 0.892 & \multirow{3}{*}{0.933} & \multirow{3}{*}{0.823} \\
\hline & INN2 & 0.901 & & \\
\hline & INN3 & 0.928 & & \\
\hline
\end{tabular}

Finally, the existence of discriminant validity was verified using two criteria. First, following Barclay, Higgins, and Thompson (1995), it was confirmed that the square root of the AVE from each construct was larger than the estimated correlations for all pairs of constructs. Second, the criteria proposed by Henseler, Ringle, and Sarstedt (2015) to assess discriminant validity among reflective constructs was applied. Following their approach, if the heterotrait-monotrait (HTMT) ratios of correlations for each pair of constructs are below 0.90 , then discriminant validity has been established between those two reflective constructs. Table 4 reports the results of the discriminant validity analyses.

The significance of the path coefficients was assessed with a bootstrapping procedure with 6.000 subsamples. The model explained $11.6 \%$ of the perceived ease of use variance, $29.4 \%$ of the perceived usefulness, $42.4 \%$ of the flow experience, and the $59.7 \%$ of the attitude towards the OBSG. The predictive relevance of the model was also confirmed through the Stone-Geisser test, which revealed that the variables' $\mathrm{Q}^{2}$ values were positive. Consequently, the predictors explain the dependent variables of the model. 
Table 4

Discriminant validity

\begin{tabular}{l|c|c|c|ccc}
\hline Construct & PE & PEU & PU & ATT & FLO & INN \\
\hline PE & 0.933 & 0.369 & 0.543 & 0.667 & 0.675 & 0.380 \\
\cline { 2 - 3 } PEU & 0.329 & 0.884 & 0.392 & 0.494 & 0.300 & 0.220 \\
PU & 0.505 & 0.352 & 0.935 & 0.730 & 0.445 & 0.218 \\
ATT & 0.618 & 0.442 & 0.676 & 0.930 & 0.484 & 0.250 \\
FLO & 0.615 & 0.263 & 0.402 & 0.440 & 0.849 & 0.363 \\
INN & 0.351 & 0.195 & 0.202 & 0.230 & 0.324 & 0.907 \\
\hline
\end{tabular}

Note. Figures on the diagonal represent the squared root of the AVE values. Values below the diagonal represent the constructs' correlations. Values above the diagonal are the HTMT values.

\section{Results}

Results of the structural model are shown in Table 5. According to the estimations of the structural model, the TAM relationships were confirmed as expected. Perceived ease of use positively influenced perceived usefulness $(\beta=0.207 ; t=3.358)$ and the attitude towards the OBSG $(\beta=0.170 ; t=3.208)$. Additionally, perceived usefulness of the OBSG was positively related to the students' attitude towards it $(\beta=0.442 ; t=$ 8.340). Overall, these finding confirm that both perceived usefulness and ease of use are significant predictors of students' attitudes towards OBSG; and that the influence of perceived usefulness in attitudes is larger than the influence of perceived usefulness.

Table 5

Results of the structural model

\begin{tabular}{|c|c|c|}
\hline & $\boldsymbol{\beta}$ & $t$-value \\
\hline \multicolumn{3}{|c|}{ Hypothesis } \\
\hline H1: Perceived enjoyment $\rightarrow$ Perceived ease of use & 0.297 & $3.734^{*}$ \\
\hline H2: Perceived enjoyment $\rightarrow$ Perceived usefulness & 0.434 & $7.027 *$ \\
\hline H3: Perceived enjoyment $\rightarrow$ Attitude & 0.335 & $5.299 *$ \\
\hline H4: Perceived enjoyment $\rightarrow$ Flow & 0.477 & $6.753 *$ \\
\hline H5: Perceived ease of use $\rightarrow$ Flow & 0.010 & 0.172 \\
\hline H6: Perceived usefulness $\rightarrow$ Flow & 0.123 & $2.017 * *$ \\
\hline H7: Flow $\rightarrow$ Attitude & -0.006 & 0.914 \\
\hline \multicolumn{3}{|l|}{$\begin{array}{ll}\text { TAM relationships } \\
\end{array}$} \\
\hline Perceived ease of use $\rightarrow$ Perceived usefulness & 0.207 & $3.358 *$ \\
\hline Perceived ease of use $\rightarrow$ Attitude & 0.170 & $3.208 *$ \\
\hline Perceived usefulness $\rightarrow$ Attitude & 0.442 & $8.340 *$ \\
\hline \multicolumn{3}{|c|}{ Moderating effects of personal innovativeness } \\
\hline H8: Innovativeness X Perceived ease of use $\rightarrow$ Attitude & -0.124 & $2.527 * *$ \\
\hline H9: Innovativeness X Perceived enjoyment $\rightarrow$ Attitude & 0.086 & 1.507 \\
\hline H10: Innovativeness X Perceived ease of use $\rightarrow$ Flow & -0.098 & $2.026 * *$ \\
\hline H11: Innovativeness X Perceived enjoyment $\rightarrow$ Flow & -0.020 & 0.526 \\
\hline $\mathbf{R}^{2}$ & $\mathbf{Q}^{2}$ & \\
\hline $\mathrm{R}^{2}(\mathrm{PEU})=0.116$ & $\mathrm{Q}^{2}(\mathrm{PEU})=0.075$ & \\
\hline $\mathrm{R}^{2}(\mathrm{PU})=0.294$ & $\mathrm{Q}^{2}(\mathrm{PU})=0.253$ & \\
\hline $\mathrm{R}^{2}(\mathrm{FLO})=0.424$ & $\mathrm{Q}^{2}(\mathrm{FLO})=0.292$ & \\
\hline $\mathrm{R}^{2}(\mathrm{ATT})=0.597$ & $\mathrm{Q}^{2}(\mathrm{ATT})=0.506$ & \\
\hline
\end{tabular}

Notes. $* p<0.01 ; * * p<0.05$. See Table 1 for abbreviations.

The results indicate that perceived enjoyment positively and significantly predicted students' perceived ease of use $(\beta=0.297 ; t=3.734)$, perceived usefulness $(\beta=0.434 ; t=7.027)$, attitude towards the game $(\beta=0.335 ; t$ $=5.299)$ and flow experience $(\beta=0.477 ; t=6.753)$. Thus, hypotheses $1-4$ were supported. Contrary to our expectations, perceived ease of use was not significantly related to students' flow experience during the game 
( $\beta=0.010 ; t=0.172$ ); thus, hypothesis 5 was rejected. By contrast, hypothesis 6 was verified since perceived usefulness significantly affected flow experience $(\beta=0.123$; $t=2.017)$. Additionally, flow did not significantly predict the students' attitudes towards the OBSG $(\beta=-0.006 ; t=0.914)$; thus hypothesis 7 was rejected.

The moderating effects were computed by employing the two-stage approach, which is preferable over other alternatives when the research is mainly interested in the significance of interaction effects (Henseler \& Chin, 2010). The results of these approaches revealed that the higher the student's personal innovativeness in ITs, the lower the effect of perceived ease of use on their attitude towards the OBSG ( $\beta=-0.124 ; t=2.527)$ and on flow experience $(\beta=-0.098 ; t=2.026)$. On the contrary, personal innovativeness did not moderate the influence of perceived enjoyment on attitude $(\beta=0.086 ; t=1.507)$ and flow $(\beta=-0.020 ; t=0.526)$.

\section{Discussion and implications for academics and instructors}

This study intended to gain a deeper understanding of the variables that determine the effectiveness of the utilisation of OBSG in college classrooms.

First, it empirically analysed effectiveness factors in the implementation of a business simulation game in an educational context. The simulation game constitutes a new technology in the business administration degree program at a major University in Spain and aims to help students to implement the theoretical knowledge learned in the degree program in an applied way. Second, it proposes an extended TAM, which considers the inclusion of relevant additional variables such as perceived enjoyment and flow experience. The results supporting the TAM (Davis, 1989) in the context of an OBSG, reinforce Bourgonjon et al.'s (2010) opinion about the critical role that perceived ease of use and usefulness have in creating students' acceptance of games in a pedagogical context. Thus, when the purpose of playing an online game goes beyond the intrinsic motivation of simply having fun, it appears that the impact of easiness and usefulness in users' attitudes should be considered. Although the literature recognises that games provide students with enjoyment while they are immersed in the activity (Ampatzoglou \& Chatzigeorgiou, 2007; Fu, Su, \& Yu, 2009), to our knowledge there is no research that simultaneously considers the above variables to better understand the individuals' level of acceptance of this technology. Third, the study suggests that experiences with and perceptions of the OBSG may differ according to the students' personality traits. Specifically, our model suggests that the students' personal innovativeness with new technologies moderates the influence of perceived ease of use on students' attitudes and experiences (Dabholkar \& Bagozzi, 2002).

The empirical results provide interesting evidence for teachers wishing to adopt or to continue using an OBSG in their classrooms. The results of the study demonstrate how enjoyment, perceived ease of use and usefulness positively influence students' attitudes towards OBSG. Besides, the results indicate that the funnier the game is for the students, the more likely it is that they will be immersed in a state of flow. Overall, these results suggest that the design of these platforms should consider not only the students' learning outcomes, but also the enjoyment component inherent in competitive games must have a primordial role in these pedagogical methodologies. In the implementation of an OBSG, instructors need to effectively organise lecturing, multimedia demonstrations, group discussions or revisions of the virtual companies' performance in order to promote learning and to facilitate the utilisation of the game (Tao et al., 2009). However, instructors should be aware that while students could perceive the OBSG as an innovative activity, it might not succeed if the complementary activities in the course methodology perpetuate the same limitations of conventional classrooms (Charsky \& Ressler, 2011). Thus, the effectiveness of games in classes will depend heavily on the attribute of enjoyment, as students expect games to be fun.

Results also indicate that perceived ease of use does not predict flow states. This could be suggesting that those students that do not perceive the OBSG easy to use may be also immersed in states of deep immersion because they need to allocate their personal resources to learn how to operate and interact with the technology. Indeed, flow did not predict attitudes towards the OBSG. This result is coherent with Lu, Zhou, and Wang's (2009) study, which reveals that higher levels of users' immersion was not directly associated with better attitudes but it significantly affected behavioural intentions. A possible explanation for this result is that, since the OBSG 
involves a utilitarian motivation for the students because they pursue to reach a specific goal, it is possible that flow experience will be associated with a feeling of losing the control of their time during the game. This loss of control could impede students from achieving their desired objectives, feeling frustrated and not forming a positive attitude towards the game. Although it is generally accepted that in mixed utilitarian-hedonic systems "time flies when you are having fun" (Agarwal \& Karahanna, 2000, p. 665), instructors should be aware that for students time could also fly when they experience states of anxiety (Pearce, Ainley, \& Howard, 2005). Therefore, games should be designed to have a level of challenge that is appropriate, and not discouragingly hard or boringly easy. This is important since the student population of digital natives (Prensky, 2001) may be more heterogeneous than expected. As suggested by Bourgonjon et al. (2010), experienced students may benefit more from the use of video games compared to their inexperienced peers.

Finally, it should be highlighted that if instructors do not pay attention to their students' diversity, less innovative students will not initially look favourably on the use of an innovative IT in their education. Specifically, the results show that the more innovative the student is, the lower the impact of perceived ease of use on the students' assessment on the game; and the less likely that perceived ease of use leads students to engage in states of flow. Consequently, teachers should be aware that more innovative students who are interested in experimenting with novel technologies will be less affected by perceived ease of use. On the contrary, for less innovative students, it is important for them to perceive that the game is easy to use. For less skilled students, intrinsic motivation to try the IT will be initially low and they might not enjoy the activity as much as their motivated peers do. Contrary to our expectations, the influence of enjoyment on attitudes and flow experience was not strengthened by personal innovativeness. An explanation for this may be that for more innovative students, fun is not as important in forming their attitudes due to the utilitarian component of the OBSG. Since highly innovative students will be more experienced in using diverse ITs, they will not be so affected by perceived enjoyment in situations where they seek to accomplish specific goals that improve their learning performance.

\section{Limitations and suggested research lines}

This study is not exempt from limitations. The empirical data were collected from only one university and specialisation, so subsequent interpretations are also limited and cannot be simply generalised to any educational use of simulation games. Considering the limitations of this study, future research could replicate our research in other universities in order to extrapolate the obtained results.

Future research should also focus on experimental designs to further explore the role of flow in students' evaluations and behavioural intentions. These approaches could elucidate how positive and negative emotions, such as enthusiasm or stress, determine flow states and attitudinal and behavioural responses. Additionally, the model should be tested in other countries and cultures, and with different business simulation games. Currently, the authors are using an improved OBSG that presents the students with new variables, challenges, different methods of communication, possibilities of cooperation between groups. Since our results indicate that students' personalities might play an important role in OBSG acceptance, further research should also analyse other traits that could have an impact on the OBSG's success, such as students' self-efficacy with computers, neuroticism, and need for interaction.

\section{References}

Agarwal, R., \& Karahanna, E. (2000). Time flies when you're having fun: Cognitive absorption and beliefs about information technology usage. MIS Quarterly, 24(4), 665-694. https://doi.org/0.2307/3250951

Agarwal, R., \& Prasad, J. (1998). A conceptual and operational definition of personal innovativeness in the domain of information technology. Information Systems Research, 9(2), 204-215. https://doi.org/10.1287/isre.9.2.204

Ahn, T., Ryu S., \& Han, I. (2007). The impact of Web quality and playfulness on user acceptance of online retailing. Information \& Management, 44(3), 263-275. https://doi.org/10.1016/j.im.2006.12.008 
Aldás-Manzano, J., Ruiz-Mafé, C., \& Sanz-Blas S. (2009). Exploring individual personality factors as drivers of M-shopping acceptance. Industrial Management \& Data, 109(6), 739-757. https://doi.org/10.1108/02635570910968018

All, A., Nuñez Castellar, E. P., \& Van Looy, J. (2015). Towards a conceptual framework for assessing the effectiveness of digital game-based learning. Computers \& Education, 88, 29-37. https://doi.org/10.1016/j.compedu.2015.04.012

All, A., Nuñez Castellar, E. P., \& Van Looy, J. (2016). Assessing the effectiveness of digital game-based learning: Best practices. Computers \& Education, 92, 90-103. https://doi.org/10.1016/j.compedu.2015.10.007

Ampatzoglou, A., \& Chatzigeorgiou, A. (2007). Evaluation of object-oriented design patterns in game development. Information and Software Technology, 49(5), 445-454. https://doi.org/10.1016/j.infsof.2006.07.003

Barclay, D., Higgins, C., \& Thompson, R. (1995). The partial least squares (PLS) approach to causal modelling: Personal computer adoption and use as an illustration. Technology Studies, 2(2), 285-309.

Bourgonjon, J., Valcke, M., Soetaert, R., \& Schellens, T. (2010). Students' perceptions about the use of video games in the classroom. Computers \& Education, 54, 1145-1156. https://doi.org/10.1016/j.compedu.2009.10.022

Boyle, E. A., Hainey, T., Connolly, T. M., Gray, G., Earp, J., Ott, M., \& Pereira, J. (2016). An update to the systematic literature review of empirical evidence of the impacts and outcomes of computer games and serious games. Computers \& Education, 94, 178-192. https://doi.org/10.1016/j.compedu.2015.11.003

Buil, I., Catalán, S., \& Martínez, E. (2017). The influence of flow on learning outcomes: An empirical study on the use of clickers. British Journal of Educational Technology. https://doi.org/10.1111/bjet.12561

Buil, I., Catalán, S., \& Martínez, E. (2018). Exploring students' flow experiences in business simulation games. Journal of Computer Assisted Learning, 34(2), 183-192). https://doi.org/10.1111/jcal.12237

Cela-Ranilla, J. M., Esteve-Mon, F. M., Esteve-González, V., \& Gisbert-Cervera, M. (2014). Developing selfmanagement and teamwork using digital games in 3D simulations. Australasian Journal of Educational Technology, 30(6). https://doi.org/10.14742/ajet.754

Charsky, D., \& Ressler, W. (2011). Games are made for fun: Lessons on the effects of concept maps in the classroom use of computer games. Computers \& Education, 56(3), 604-615. https://doi.org/10.1016/j.compedu.2010.10.001

Csikszentmihalyi, M. (1990). Flow: The psychology of optimal experience. New York, NY: Harper \& Row.

Dabholkar, P. A., \& Bagozzi, R. P. (2002). An attitudinal model of technology-based self-service: Moderating effects of consumer traits and situational factors. Journal of the Academy of Marketing Science, 30(3), 184-201. https://doi.org/10.1177/0092070302303001

Davis, F. (1989). Perceived usefulness, perceived ease of use and user acceptance of information technology. MIS Quarterly, 13(3), 319-340. https://doi.org/10.2307/249008

Davis, F. D., Bagozzi, R. P., \& Warshaw, P. R. (1992). Extrinsic and intrinsic motivation to use computers in the workplace. Journal of Applied Social Psychology, 22(14), 1111-1132. https://doi.org/10.1111/j.15591816.1992.tb00945.X

Filippou, J., Cheong, C., \& Cheong, F. (2018). A Model to Investigate Preference for Use of Gamification in a Learning Activity. Australasian Journal of Information Systems, 22. https://doi.org/10.3127/ajis.v22i0.1397

Finneran, C. M., \& Zhang, P. (2003). A person-artefact-task (PAT) model of flow antecedents in computermediated environments. International Journal of Human-Computer Studies, 59(4), 475-496. https://doi.org/10.1016/S1071-5819(03)00112-5

Fornell, C., \& Larcker, D. F. (1981). Evaluating structural equation models with unobservable variables and measurement error. Journal of Marketing Research, 18(1), 39-50. https://doi.org/10.2307/3151312

Fu, F., Su, R., \& Yu, S. (2009). EGameFlow: A scale to measure learners' enjoyment of e-learning games. Computers \& Education, 52(1), 101-112. https://doi.org/10.1016/j.compedu.2008.07.004

Gao, S., Krogstie, J., \& Zang, Z. (2016). The effect of flow experience and social norms on the adoption of mobile games in China. International Journal of Mobile Human Computer Interaction, 8(1), 83-102. https://doi.org/0.4018/IJMHCI.2016010104 
Ha, I., Yoon, Y., \& Choi, M. (2007). Determinants of adoption of mobile games under mobile broadband wireless access environment. Information \& Management, 44(3), 276-286. https://doi.org/10.1016/j.im.2007.01.001

Hair, J. F., Ringle, C. M., \& Sarstedt, M. (2011). PLS-SEM: Indeed a silver bullet. Journal of Marketing Theory and Practice, 19(2), 139-152. https://doi.org/10.2753/MTP1069-6679190202

Hamari, J., Shernoff, D. J., Rowe, E., Coller, B., Asbell-Clarke, J., \& Edwards, T. (2016). Challenging games help students learn: An empirical study on engagement, flow and immersion in game-based learning. Computers in Human Behavior, 54, 170-179. https://doi.org/10.1016/j.chb.2015.07.045'

Henseler, J., \& Chin, W. (2010). A comparison of approaches for the analysis of interaction effects between latent variables using partial least squares path modeling. Structural Equation Modeling, 17(1), 82-109. https://doi.org/10.1080/10705510903439003

Henseler, J., Ringle, C. M., \& Sarstedt, M. (2015). A new criterion for assessing discriminant validity in variance-based structural equation modeling. Journal of the Academy of Marketing Science, 43(1), 115135. https://doi.org/10.1007/s11747-014-0403-8

Herrington, J., Oliver, R., \& Reeves, T. C. (2003). Patterns of engagement in authentic online learning environments. Australasian Journal of Educational Technology, 19(1). https://doi.org/10.14742/ajet.1701

Hsu, C., \& Lu, H. (2004). Why do people play on-line games? An extended TAM with social influences and flow experience. Information \& Management, 41(7), 853-868. https://doi.org/10.1016/j.im.2003.08.014

Kiili, K. (2005). Digital game-based learning: Towards an experiential gaming model. Internet and Higher Education, 8(1), 13-24. https://doi.org/10.1016/j.iheduc.2004.12.001

Koivisto, J., \& Hamari, J. (2014). Demographic differences in perceived benefits from gamification. Computers in Human Behavior, 35, 179-188. https://doi.org/10.1016/j.chb.2014.03.007

Lai, M., Lim, C. P., \& Wang, L. (2016). Potential of digital teaching portfolios for establishing a professional learning community in higher education. Australasian Journal of Educational Technology, 32(2), 1-14. https://doi.org/10.14742/ajet.2572

Lauricella, A. R., Blackwell, C. K., \& Wartella, E. (2017). The "New” technology environment: The role of content and context on learning and development from mobile media. In R. Barr \& D.N. Linebarger (Eds.), Media exposure during infancy and early childhood (pp. 1-23). Cham: Springer.

Lee, H. Y., Ahn, H., \& Han, I. (2007). VCR: Virtual community recommender using the technology acceptance model and the user's needs type. Expert Systems with Applications, 33(4), 984-995. https://doi.org/10.1016/j.eswa.2006.07.012

Lee M., Cheung, C., \& Chen, Z. (2005). Acceptance of Internet-based learning medium: The role of extrinsic and intrinsic motivation. Information \& Management, 42(8), 1095-1104. https://doi.org/10.1016/j.im.2003.10.007

Lu, Y., Zhou, T., \& Wang, B. (2009). Exploring Chinese users' acceptance of instant messaging using the theory of planned behavior, the technology acceptance model, and the flow theory. Computers in Human Behavior, 25(1), 29-39. https://doi.org/10.1016/j.chb.2008.06.002

Novak, T., Hoffman, D., \& Yung, Y. (2000). Measuring the customer experience in online environment: a structural modelling approach. Marketing Science, 19(1), 22-44. https://doi.org/10.1287/mksc.19.1.22.15184

Pando-García, J., Periañez-Cañadillas, I., \& Charterina, J. (2016). Business simulation games with and without supervision: An analysis based on the TAM model. Journal of Business Research, 69(5), 17311736. https://doi.org/10.1016/j.jbusres.2015.10.046

Pearce, J. M., Ainley, M., \& Howard, S. (2005). The ebb and flow of online learning. Computers in Human Behavior, 21(5), 745-771. https://doi.org/10.1016/j.chb.2004.02.019

Podsakoff, P. M., MacKenzie, S., Lee, J., \& Podsakoff, N. (2003). Common method biases in behavioral research: a critical review of the literature and recommended remedies. Journal of Applied Psychology, 88(5), 879-903. https://doi.org/10.1037/0021-9010.88.5.879

Prensky, M. (2001). Digital natives, digital immigrants: Part I. On the Horizon 9(5), 1-6. https://doi.org/10.1108/10748120110424816

Ranchhod, A., Gurău, C., Loukis, E., \& Trivedi, R. (2014). Evaluating the educational effectiveness of simulation games: A value generation model. Information Sciences, 264, 75-90.

https://doi.org/10.1016/j.ins.2013.09.008 
Reinartz, W., Haenlein, M. and Henseler, J. (2009). An empirical comparison of the efficacy of covariancebased and variance-based SEM. International Journal of Research in Marketing, 26(4), 332-344. https://doi.org/10.1016/j.ijresmar.2009.08.001

Roca, J., Chiu, C., \& Martínez, J. (2006). Understanding e-learning continuance intention: An extension of the Technology Acceptance Model. International Journal of Human-Computer Studies 64(8), 683-696. https://doi.org/10.1016/j.ijhcs.2006.01.003

Roldán, J. L., \& Sánchez-Franco, M. J. (2012). Variance-based structural equation modeling: Guidelines for using partial least squares in information systems research. In M. Mora, O. Gelman, A. Steenkamp, \& M. Raisinghani (Eds.), Research methodologies, innovations, and philosophies in software systems engineering and information systems (pp. 193-221). Hershey, PA: IGI Global. https://doi.org.10.4018.978-1-4666-0179-6.cb010

Smets, N. J. J. M., Abbing, M. S., Neerincx, M. A., Lindenberg, J., \& van Oostendorp, H. (2010). Gamebased versus storyboard-based evaluations of crew support prototypes for long duration missions. Acta Astronautica, 66(5), 810-820. https://doi.org/10.1016/j.actaastro.2009.08.032

Sun, H., \& Zhang, P. (2006). Causal relationships between perceived enjoyment and perceived ease of use: an alternative approach. Journal of the Association for Information Systems, 7(9), 618-645. http://aisel.aisnet.org/jais/vol7/iss9/24

Tao, Y. H., Cheng, C. J., \& Sun, S. Y. (2009). What influences college students to continue using business simulation games? The Taiwan experience. Computers \& Education, 53(3), 929-939. https://doi.org/10.1016/j.compedu.2009.05.009

Teo, T., \& Noyes, J. (2011). An assessment of the influence of perceived enjoyment and attitude on the intention to use technology among pre-service teachers: A structural equation modelling approach. Computers \& Education, 57(2), 1645-1653. https://doi.org/10.1016/j.compedu.2011.03.002

Venkatesh, V. (2000). Determinants of perceived ease of use: Integrating control, intrinsic motivation, and emotion into the technology acceptance model. Information Systems Research, 11(4), 342-365. https://doi.org/10.1287/isre.11.4.342.11872

Venkatesh, V., Speier, C., \& Morris, M.G., (2002). User acceptance enablers in individual decision making about technology: toward an integrated model. Decision Sciences, 33(2), 297-316. https://doi.org/10.1111/j.1540-5915.2002.tb01646.x

Wellington, W. J., Hutchinson, D. B., \& Faria, A. J. (2017). Measuring the impact of a marketing simulation game: Experience on perceived indecisiveness. Simulation \& Gaming, 48(1), 56-80. https://doi.org/10.1177/1046878116675103

Wild, T. C., Kuiken, D., \& Schopflocher, D. (1995). The role of absorption in experiential involvement. Journal of Personality and Social Psychology, 69(3), 569-579. http://dx.doi.org/10.1037/0022$\underline{3514.69 .3 .569}$

Wu, J., \& Liu, D. (2007). The effects of trust and enjoyment on intention to play online games. Journal of Electronic Commerce Research, 8(2), 128-140. http://www.jecr.org/node/159

Zhou, T. (2013). The effect of flow experience on user adoption of mobile TV. Behaviour \& Information Technology, 32(3), 263-272. https://doi.org/10.1080/0144929X.2011.650711

Corresponding author: Jorge Matute-Vallejo, jorge.matute@iqs.url.edu

Australasian Journal of Educational Technology (c) 2019.

Please cite as: Matute-Vallejo, J., \& Melero-Polo, I. (2019). Understanding online business simulation games: The role of flow experience, perceived enjoyment and personal innovativeness. Australasian Journal of Educational Technology, 35(3), 71-85. https://doi.org/10.14742/ajet.3862 